\title{
Determination of Tannins of Three Common Acacia Species of Sudan
}

\author{
Isam Eldin Hussein Elgailani and Christina Yacoub Ishak \\ Department of Chemistry, Faculty of Science, University of Khartoum, P.O Box 321, 11115 Khartoum, Sudan \\ Correspondence should be addressed to Isam Eldin Hussein Elgailani; gailani23@hotmail.com
}

Received 8 June 2014; Accepted 7 September 2014; Published 17 September 2014

Academic Editor: Armando Zarrelli

Copyright (C) 2014 I. E. H. Elgailani and C. Y. Ishak. This is an open access article distributed under the Creative Commons Attribution License, which permits unrestricted use, distribution, and reproduction in any medium, provided the original work is properly cited.

\begin{abstract}
The objective of this study is to analyze and compare tannins of three common Acacia species of Sudan, since vegetable tannins are important in leather industry. Acacia nilotica and Acacia seyal samples were collected from Sunt Forest in Khartoum State, while Acacia senegal samples were collected from the Debabat Forest in South Kordofan State. Bark samples from bulk collections of the three Acacia species were extracted with boiled deionized water. The amount of tannins present in these bulk samples was determined by Folin-Denis method for total phenolic materials, followed by precipitation with hide-powder. The difference between the amount of phenolic materials present before and after addition of hide-powder represents the amount of tannins present. The percentage of tannins in the leaves, bark, and mature and immature fruits of collections of individuals of Acacia species was estimated; mature and immature fruits of Acacia nilotica contain tannins (22.15\% and $22.10 \%$, resp.). The leaves of Acacia nilotica and Acacia seyal contain tannins (11.80\% and 6.30\%, resp.). The barks of Acacia seyal, Acacia nilotica, and Acacia senegal contain tannins $(12.15 \%, 10.47 \%$, and $3.49 \%$, resp.).
\end{abstract}

\section{Introduction}

Tannins are amorphous, astringent substances occurring widely in the bark, wood, leaves, and resinous exudations of plants $[1,2]$. They are water-soluble phenolic compounds which occur widely in vascular plants [3]. The term was introduced by Seguim in 1796 to describe the substances present in a number of vegetable extracts which possessed the property of converting animal skins into leather [4]. Most authors prefer to speak of "tannin extracts" rather than "tannin." The tannins are colourless and noncrystalline substances which form colloidal solutions in water; these solutions have an astringent taste $[5,6]$. The astringency of tannins, that is, their efficiency as precipitants of proteins in the mouth causing the sensation of astringency [7-9], is determined by their reaction with salivary proteins in the oral cavity [10]. Astringency and tanning properties are associated with the higher molecular weight proanthocyanidins (condensed tannins) [11]. Tannins are polymeric phenolic compounds with numerous hydroxyl groups and quite diverse in chemical structure $[12,13]$. Hydrolysis of some of the tannins yields the simple, seven-carbon gallic acid and others give ellagic acid or other phenolic acids $[14,15]$. Tannins are generally divided into hydrolyzable and condensed tannins. Molecular weight as high as 20,000 has been reported for condensed tannins. The molecular weights of hydrolyzable tannins range from 500 to $5,000[13,16-18]$. Beside the variation from plant to plant, and from one part of a plant to another, the concentration of tannins in any one organ varies with time [19]. The use of vegetable tannins to tan hides and produce leather predates written history. Hides are usually tanned by either a mineral [20] or vegetable process, depending on the type of animal and the extended use of the leather. In Sudan, approximately $11,400,000 \mathrm{~kg}$ of cattle hides and $3,750,000 \mathrm{~kg}$ of sheep hides are tanned each year (by both processes). Vegetable tannins consumption in Sudan varies between 350 and 400 tons per year, and a large proportion is locally produced as the Acacia species is more distributed in Sudan (data were obtained from the National Centre for Leather Technology and Khartoum Tannery). One of the best sources of tannins is Acacia species which belong to family of Leguminosae in plant kingdom. There are about 800 species 
of the genus Acacia. They are abundant in savannas and arid regions [21]. The commercial wattle grown in Kenya (Acacia mearnsii) is a well-known tannin-rich species and tanninbased adhesive $[22,23]$. Tannins are complexed with the proteins of the hide and become an integral part of the final product. The ability of tannins to complex with proteins is largely responsible for the production of leather from hide [24]. In this work, we initiated this study in order to identify sources of tannins that grow in Sudan and to determine the amount of tannins present and the distribution of these compounds in different parts of the plants involved. Three common species, Acacia nilotica, Acacia seyal, and Acacia senegal, were selected for study.

\section{Material and Methods}

2.1. Study Area. Acacia nilotica and Acacia seyal samples were collected from the Sunt Industrial and Tourism Centre (Sunt Forest), about 1 kilometer south of the White Nile Bridge near the junction of White Nile and Blue Nile on the eastern bank of the White Nile River at Khartoum State, while the Acacia senegal samples were collected from Debabat Forest in South Kordofan State at West of Sudan.

2.2. Sampling Methodology. Samples of leaves, bark, and mature and immature fruits from individual collections of Acacia nilotica (leaves, bark, and mature and immature fruits), Acacia seyal (leaves and bark), and Acacia senegal (bark only) were used to determine the tannins. Bark was removed from wood before drying. Plant materials were taken from several trees in each instance.

2.3. Chemicals and Reagents. All chemicals and reagents used in this study were of analytical grade.

2.4. Extraction of Bark Samples. Air-dried bark samples (from bulk collections) were ground in a Wiley mill ( $2 \mathrm{~mm}$ screen). A portion ( $40 \mathrm{~g}$ ) was extracted with boiled deionized water $(200 \mathrm{~mL}$ ). The samples were filtered (Whatman 1 paper, $18.5 \mathrm{~cm}$ disc) and the residual material was rinsed with additional water $(2 \times 50 \mathrm{~mL})$. Extracts were transferred to a tarred, round-bottomed flask and concentrated under vacuum by rotary evaporator to form a thick extract. The sample extracts were then dried in a vacuum oven at $60^{\circ} \mathrm{C}$ until a solid material was obtained.

2.5. Determination of Total Phenolic Compounds. Total phenolic compounds were measured in plant samples by the Folin-Denis method [25]. Folin-Denis reagent was prepared by mixing $\mathrm{Na}_{2} \mathrm{WO}_{4} \cdot 2 \mathrm{H}_{2} \mathrm{O}(20.66 \mathrm{~g})$, dodeca-molybdophosphoric acid $(4.13 \mathrm{~g})$, phosphoric acid $(85 \%, 10 \mathrm{~mL})$, and water $(150 \mathrm{~mL})$ and permitting the mixture to reflux for two hours. The resulting solution was then diluted to $500 \mathrm{~mL}$. Sodium carbonate solution was prepared by dissolving $\mathrm{Na}_{2} \mathrm{CO}_{3}(106 \mathrm{~g})$ in $1000 \mathrm{~mL}$ of water. Solution of tannic acid (6\% water content) was then prepared by dissolving the tannin $(250 \mathrm{mg})$ in double distilled water $(500 \mathrm{~mL})$. A small amount (2-3 drops) of sodium azide solution ( $0.1 \%)$ was

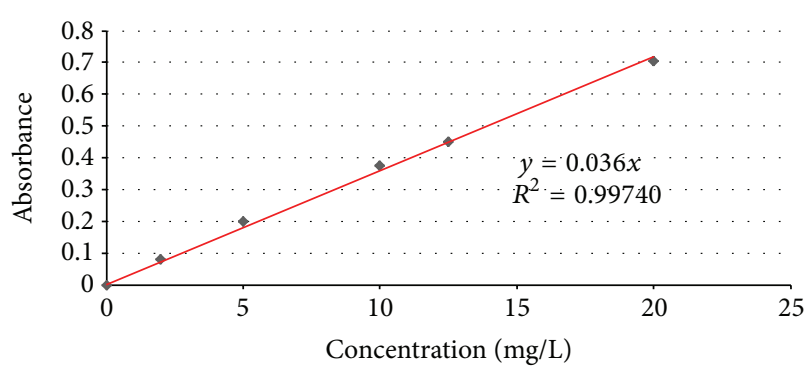

FIgURE 1: Absorbance of solutions of tannic acid as a function of concentrations.

added to prevent contamination by fungi and bacteria. Before use, aliquot of this solution was diluted 1:100 with double distilled water.

Folin-Denis reagent $(2 \mathrm{~mL})$ was added to an aliquot $(2 \mathrm{~mL})$ of the 1:100 dilution described above. The solution was shaken vigorously and allowed to stand for three minutes. Sodium carbonate solution $(2 \mathrm{~mL})$ was added and the sample again was shaken and allowed to stand for two hours. At that time, the sample was centrifuged at low speed until particulate materials have been removed. The absorbance was measured at $725 \mathrm{~nm}$ by UV/VIS Spectrophotometer (PerkinElmer 551). A blank was also analyzed in each instance. By a series of dilutions of the tannin solutions prepared $(1: 250$, $1: 50,1: 40,1: 25$, and $1: 10$ ), a curve was plotted for tannic acid (Figure 1).

The phenolic content of each sample was measured by the Folin-Denis method as described above. Duplicate determinations were carried out for each sample (Tables 1 and 2).

2.6. Determination of Tannins by the Hide-Powder Method. The determination of tannins consists of 4 steps: (i) measurement of total phenolic material in plant samples extracts by Folin-Denis method, (ii) preparation of hydrated, chromed, hide-powder, (iii) absorption of tannins onto hide-powder, and (iv) determination of phenolic materials in the solution remaining after step (iii).

Hydrated hide-powder used in these analyses was prepared from air-dried hide-powder (brought from the National Center for Leather Technology, Khartoum). Sufficient air-dried hide-powder to yield $3.0 \mathrm{~g}$ oven-dried hidepowder was used for each analysis performed. The amount of hide-powder necessary to perform the desired number of analyses was allowed to stand with 10 times its weight of distilled water $\left(30 \mathrm{~min} ., 25^{\circ} \mathrm{C}\right)$ and was stirred 3 or 4 times during this period. Chromium potassium sulphate (chrome alum, $3 \%$ aqueous solution, $1 \mathrm{~g} / \mathrm{mL}$ hide-powder) was added and the mixture was stirred each 15 minutes for two hours, allowed to stand overnight, and then filtered through a piece of unbleached, white cotton cloth and was squeezed or pressed until the hydrated powder contained about $75 \%$ water (when new cloth was used, it was washed to remove sizing and other extraneous materials). The percentage of water in the hydrated hide-powder was determined by weight (4 times the weight of the total hide-powder plus the weight 
TABLE 1: Absorbance of solution of Acacia species parts before precipitation of tannins with hydrated-hide powder (at $725 \mathrm{~nm}$ ).

\begin{tabular}{lcccc}
\hline Species & Plant part & I & \multicolumn{2}{c}{ Absorbance } \\
II & 0.255 & Average value \\
\hline Acacia nilotica & & 0.251 & 0.126 & 0.253 \\
Acacia seyal & Leaves & 0.128 & 0.202 & 0.127 \\
Acacia nilotica & Leaves & 0.205 & 0.232 & 0.203 \\
Acacia seyal & Bark & 0.232 & 0.081 & 0.232 \\
Acacia senegal & Bark & 0.081 & 0.463 & 0.081 \\
Acacia nilotica & Bark & 0.461 & 0.444 & 0.442 \\
Acacia nilotica & Mature fruits & 0.439 & & \\
\hline
\end{tabular}

TABLE 2: Absorbance of solutions of Acacia species parts after precipitation of tannins with hydrated-hide powder (at $725 \mathrm{~nm}$ ).

\begin{tabular}{lcccc}
\hline Species & Plant part & I & \multicolumn{2}{c}{ Absorbance } \\
II & 0.053 & Average value \\
\hline Acacia nilotica & Leaves & 0.053 & 0.309 & 0.053 \\
Acacia seyal & Leaves & 0.308 & 0.241 & 0.308 \\
Acacia nilotica & Bark & 0.239 & 0.276 & 0.240 \\
Acacia seyal & Bark & 0.273 & 0.338 & 0.274 \\
Acacia senegal & Bark & 0.340 & 0.065 & 0.339 \\
Acacia nilotica & Mature fruits & 0.060 & 0.056 & 0.053 \\
Acacia nilotica & Immature fruits & 0.056 & & 0 \\
\hline
\end{tabular}

of cloth). The mass of hide-powder was then broken up and redigested with water 4 times (15 minutes each) in amount of water 15 times the weight of hide-powder used. After the final wash, the hide-powder was squeezed to $72.5 \%$ water content (determined by weight). Hide-powder prepared in this manner should be refrigerated and used the same day as prepared.

2.6.1. Determination of Water in Hydrated Hide-Powder Samples. An aliquot (10 g) of hydrated hide-powder was removed and placed in an oven $\left(98^{\circ} \mathrm{C}\right)$ and dried for 17 hours. The difference in weight was used to calculate the percentage water in the sample.

2.6.2. Precipitation of Tannins with Hydrated Hide-Powder. Freshly prepared, hydrated hide-powder, equivalent to $3.0 \mathrm{~g}$ oven-dried hide-powder, was weighed and added to an Erlenmeyer flask $(150 \mathrm{~mL})$. Solutions for the determination of tannins by the hide-powder method were prepared by dissolving commercial tannin samples as above in doubled distilled water $(500 \mathrm{mg} / \mathrm{L})$. Solutions of plant extracts were prepared in a similar manner. Solution should be stored refrigerated and small amount (2-3 drops) of $0.1 \%$ sodium azide solution was added to prevent fungal or bacterial contamination. Solutions were at room temperate when used.

Aliquots of tannin solutions $(50 \mathrm{~mL})$ were removed and added to the flasks that contained preweighed hide-powder samples (10.9 $\mathrm{g}$ for the conditions outlined above). The flasks were then shaken for ten minutes and the hide-powder was removed by filtration. The mixture was filtered into a flask with plastic Buchner funnel $(7.0 \mathrm{~cm}$, Whatman 1 paper) under vacuum. The flask and the sample were washed with double distilled water $(10 \mathrm{~mL})$. Cloudy solutions were refiltered. After filtration, the filtrate (about $60 \mathrm{~mL}$ ) was quantitatively transferred to a volumetric flask and adjusted to $100 \mathrm{~mL}$. Blanks were run with distilled water and with hydrated hide-powder. Aliquots $(2 \mathrm{~mL})$ were then removed from each sample and residual phenolic materials determined by the Folin-Denis method (Table 2).

2.7. Determination of Tannins in Leaves, Bark, and Mature and Immature Fruits. Samples of leaves, bark, and mature and immature fruits material of Acacia nilotica, Acacia seyal, and Acacia senegal were ground and extracted. $10.0 \mathrm{~g}$ of the quantity ground was extracted with double distilled water $(100 \mathrm{~mL})$ in an Erlenmeyer flask $(150 \mathrm{~mL})$ by mechanical stirring and heating. The mixture was heated to boiling for 10 minutes and filtered (Whatman $1,18.5 \mathrm{~cm}$ ). The flask and filtered material were then rinsed with additional water $(15 \mathrm{~mL})$ and the volume was adjusted to $100 \mathrm{~mL}$. Aliquots of this initial extract were then removed and diluted to an appropriate concentration for Folin-Denis analysis, which was carried out in the manner previously described.

For the determination of tannins by the hide-powder method an aliquot of the initial extract was diluted as above (to give 0.05-0.2 absorbance units after precipitation with hide-powder). An aliquot of this solution $(50 \mathrm{~mL})$ was then utilized as previously described.

\section{Results and Discussions}

Folin-Denis reagent is a mixture of phosphotungstic phosphomolybdic acids, and when this labile complex acid is reduced by phenols, a blue tungstic oxide is obtained [26], 
Table 3: Tannins percentage of Acacia species parts.

\begin{tabular}{lcccc}
\hline Species & Plant part & \% Phenolics before precipitation & \% Phenolics after precipitation & \% Tannins (hide-powder) \\
\hline Acacia nilotica & Leaves & 14.00 & 2.20 & 11.80 \\
Acacia seyal & Leaves & 7.00 & 0.69 & 6.31 \\
Acacia nilotica & Bark & 11.00 & 0.53 & 10.47 \\
Acacia seyal & Bark & 12.75 & 0.60 & 12.15 \\
Acacia senegal & Bark & 4.25 & 0.76 & 3.49 \\
Acacia nilotica & Mature fruits & 24.75 & 2.60 & 22.15 \\
Acacia nilotica & Immature fruits & 24.50 & 2.40 & 22.10 \\
\hline
\end{tabular}

* Total phenolic content relative to tannic acid.

which was measured spectrophotometrically at $725 \mathrm{~nm}[18$, 24]. The amount of tannins is determined by the preparation of tannins solutions and absorption of the tannins on hydrated, chromed hide-powder. The difference in the phenolic materials, as indicated by the Folin-Denis analysis before and after treatment with hydrated, chromed hidepowder, is utilized to measure tannins. Phenolic compounds of different structures give response to Folin-Denis reagent. All results in this study have been expressed in terms of tannic acid equivalents. Inspection of curve for tannic acid suggests that this technique may underestimate the quantity of tannins present.

As indicated by the Folin-Denis method, the major portion of phenolics in these Acacia species consists of tannins (Table 3). Small differences in the amount of residual phenolic materials after precipitation of tannins with hidepowder have a relatively small effect on calculation of the percentage of tannins present in the original plant material.

Comparison of the amount of tannins present in the leaves, bark, and mature and immature fruits of the species was made with aqueous extracts of samples collected from single individual (Table 3). Total phenolic materials were richest in mature and immature fruits, leaves, and bark of Acacia nilotica and Acacia seyal. They were lower in the bark of Acacia senegal. The same trends are observed for tannins. Additional studies will be necessary to estimate variation within and among population of each species. The results showed that mature and immature fruits of Acacia nilotica had the highest percentage of tannins $(22.15 \%$ and $22.10 \%$, resp.), while the leaves and the bark of the same species had $11.8 \%$ and $10.47 \%$, respectively. The leaves and the bark of Acacia seyal had intermediate values $(6.32 \%$ and $12.15 \%$, resp.). The bark of Acacia senegal had much lower percentage of tannins (3.49\%) (Table 3).

\section{Conclusions}

We can conclude that, among the three Acacia species studied, Acacia nilotica is the richest in tannins content, and within the Acacia nilotica parts, mature and immature fruits were the highest in tannins content, while the barks of the three Acacia species were the least. Folin-Denis method for total phenolic materials, followed by precipitation of tannins by hide-powder, is a suitable procedure for evaluation of tannins content.
Recommendations that could be drawn from this study are that additional studies will be necessary to estimate variation within and among population of each species. Suggestions are made for further studies on the possible mode of linkage and the conformation of the molecules of tannins, since condensed tannins occur in plants in various stages of polymerization, and this is very important for the synthesis of tannins. Since tannins are antifungal, antibacterial, and antiviral agents, further studies may also be required to apply them in medicines in wide range.

\section{Conflict of Interests}

The authors declare that there is no conflict of interests regarding the publication of this paper.

\section{Acknowledgments}

Special thanks are to the Department of Chemistry, University of Khartoum, where the current evaluation and investigation have been carried out, for laboratory facilities and valuable assistance in the use of various types of equipment. Thanks are extended to the National Centre for Leather Technology, Khartoum Tannery and White Nile Tannery, for continuous help during the course of the study.

\section{References}

[1] J. Read, A Text-Book of Organic Chemistry, G. Bell and Sons, London, UK, 1946.

[2] J. Zivkovic, I. Mujic, Z. Zekovic, G. Nikolic, S. Vidovic, and A. Mujic, "Extraction and analysis of condensed tannins in Castanea sativa Mill," Journal of Central European Agriculture, vol. 10, no. 3, pp. 283-288, 2009.

[3] J. S. Martin and M. M. Michael, "Tannin assays in ecological studies Precipitation of ribulose-1,5-bisphosphate carboxylase/oxygenase by tannic acid, quebracho, and oak foliage extracts," Journal of Chemical Ecology, vol. 9, no. 2, pp. 285-294, 1983.

[4] T. Swain, Plant Biochemistry, Academic Press, London, UK, 1965.

[5] P. Bernfield, Biogenesis of Natural Compounds, Pergamon Press, New York, NY, USA, 1963.

[6] I. L. Finar, Organic Chemistry, Volume 2, Longman, London, UK, 1964. 
[7] E. C. Bate-Smith, "Haemanalysis of tannins: the concept of relative astringency," Phytochemistry, vol. 12, no. 4, pp. 907-912, 1973.

[8] E. Haslam, "Polyphenol protein interactions," Biochemical Journal, vol. 139, no. 1, pp. 285-288, 1974.

[9] E. C. Bate-Smith, "Astringent tannins of the leaves of Geranium species," Phytochemistry, vol. 20, no. 2, pp. 211-216, 1981.

[10] T. N. Asquith, J. Uhlig, H. Mehansho, L. Putman, D. M. Carlson, and L. Butler, "Binding of condensed tannins to salivary proline-rich glycoproteins: the role of carbohydrate," Journal of Agricultural and Food Chemistry, vol. 35, no. 3, pp. 331-334, 1987.

[11] Z. Czochanska, L. Y. Foo, R. H. Newman, and L. J. Porter, "Polymeric proanthocyanidins. Stereochemistry, structural units, and molecular weight," Journal of the Chemical Society, Perkin Transactions, vol. 1, pp. 2278-2286, 1980.

[12] V. A. Greulach, Plant Function and Structure, Collier Macmillan International Edition, New York, NY, USA, 1973.

[13] A. E. Hagerman, “Tannin-protein interactions," ACS Symposium Series, vol. 506, pp. 236-247, 1992.

[14] E. Sondheimer and J. B. Simeone, Chemical Ecology, Academic Press, New York, NY, USA, 1970.

[15] T. Okuda and H. Ito, "Tannins of constant structure in medicinal and food plants-hydrolyzable tannins and polyphenols related to tannins," Molecules, vol. 16, no. 3, pp. 2191-2217, 2011.

[16] K. Nakanishi, T. Goto, S. Ito, S. Natori, and S. Nozoe, Natural Products Chemistry, Academic Press, New York, NY, USA, 1975.

[17] T. C. Somers, "Wine tannins-isolation of condensed flavonoid pigments by gel-filtration," Nature, vol. 209, no. 5021, pp. 368370, 1966.

[18] J. S. Martin and M. M. Martin, "Tannin assays in ecological studies: lack of correlation between phenolics, proanthocyanidins and protein-precipitating constituents in mature foliage of six oak species," Oecologia, vol. 54, no. 2, pp. 205-211, 1982.

[19] M. Thomas, S. L. Ranson, and J. A. Richardson, Plant Physiology, Longman, London, UK, 1973.

[20] M. Sathiyamoorthy, V. Selvi, D. Mekonnen, and S. Habtamu, "Preparation of eco-friendly leather by process modifications to make pollution free tanneries," Journal of Engineering Computers \& Applied Sciences, vol. 2, no. 5, pp. 17-22, 2013.

[21] K. O. Rachie and National Academy of Sciences (NAS), Tropical Legumes: Resources for the Future, National Academy of Science, Washington, DC, USA, 1979.

[22] J. Z. A. Mugedo and P. G. Waterman, "Sources of tannin: alternatives to wattle (Acacia mearnsii) among indigenous Kenyan species," Economic Botany, vol. 46, no. 1, pp. 55-63, 1992.

[23] T. Sellers and G. D. Miller, "Laboratory manufacture of high moisture southern pine strandboard bonded with three tannin adhesive types," Forest Products Journal, vol. 54, no. 12, pp. 296301, 2004.

[24] D. S. Seigler, S. Seilheimer, J. Keesy, and H. F. Huang, “Tannins from four common Acacia species of Texas and Northeastern Mexico," Economic Botany, vol. 40, no. 2, pp. 220-232, 1986.

[25] T. Swain and J. L. Goldstein, "The quantitative analysis of phenolic compounds," in Methods in Polyphenol Chemistry, J. B. Pridham, Ed., Permagon, New York, NY, USA, 1964.

[26] F. D. Snell and C. T. Snell, Colorimetric Methods of Analysis, vol. 2, D. Van Nostrand Company, New York, NY, USA, 1937. 

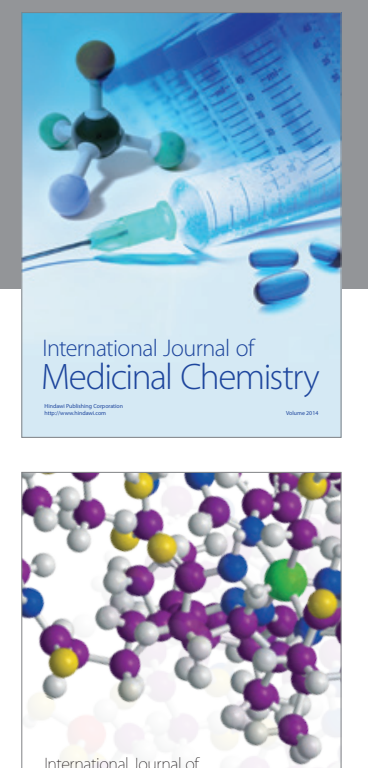

\section{Carbohydrate} Chemistry

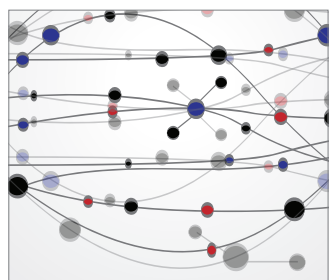

The Scientific World Journal
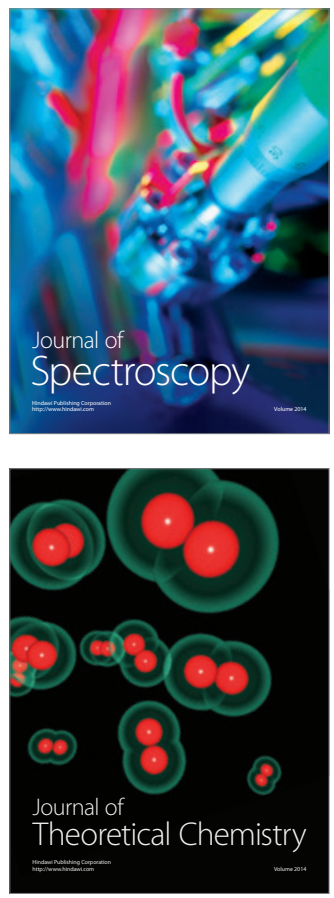
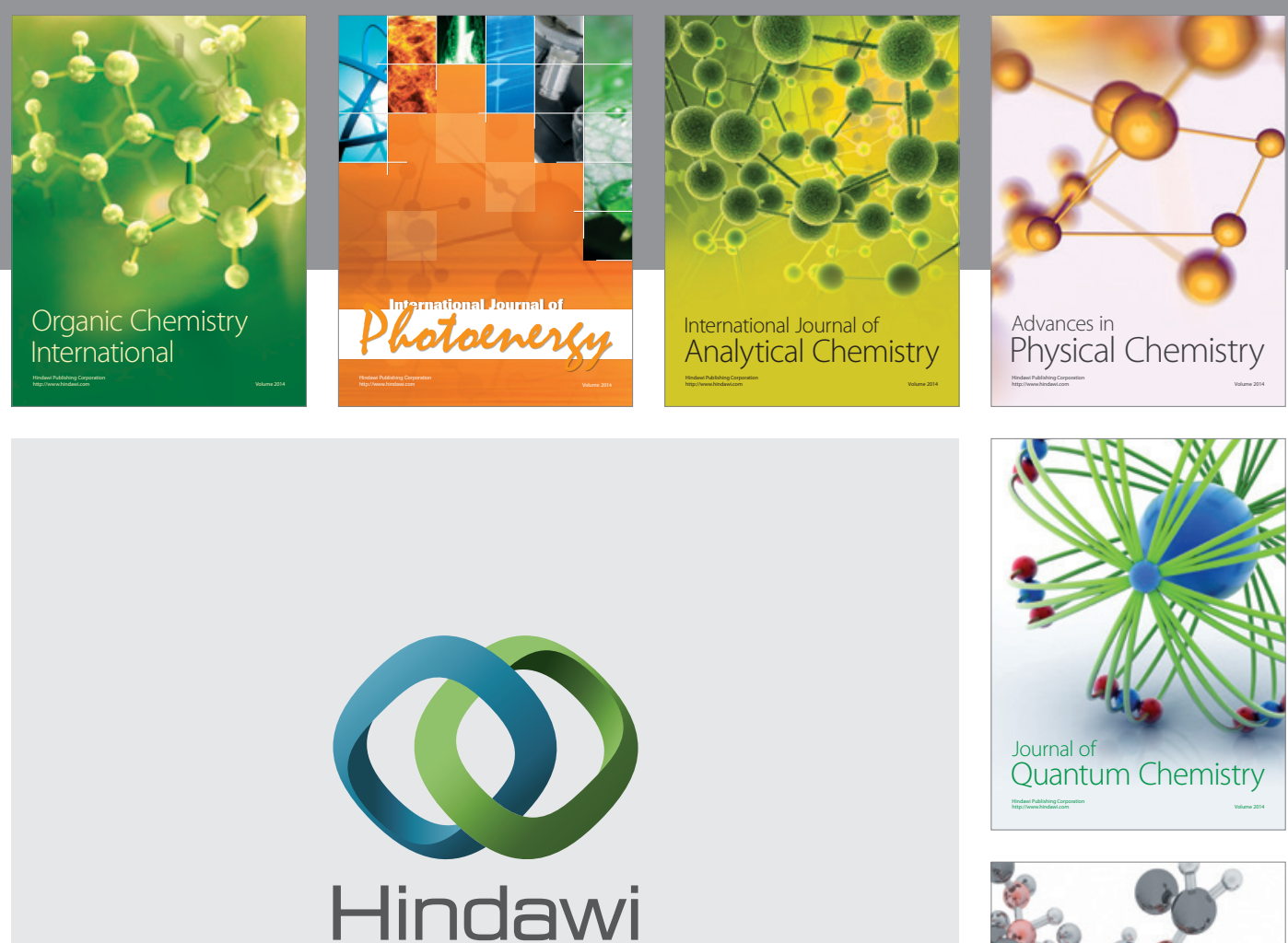

Submit your manuscripts at

http://www.hindawi.com

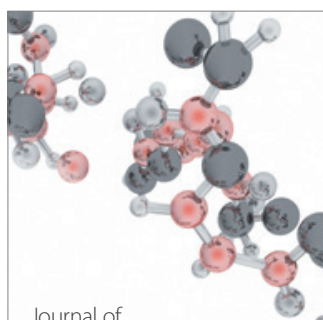

Analytical Methods

in Chemistry

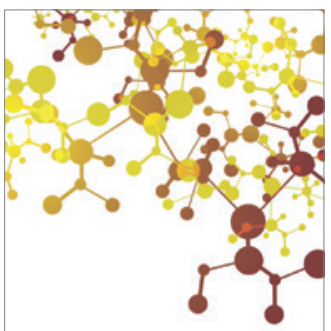

Journal of

Applied Chemistry

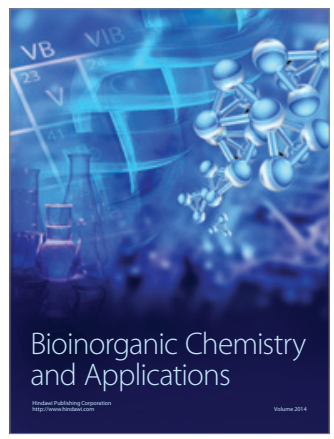

Inorganic Chemistry
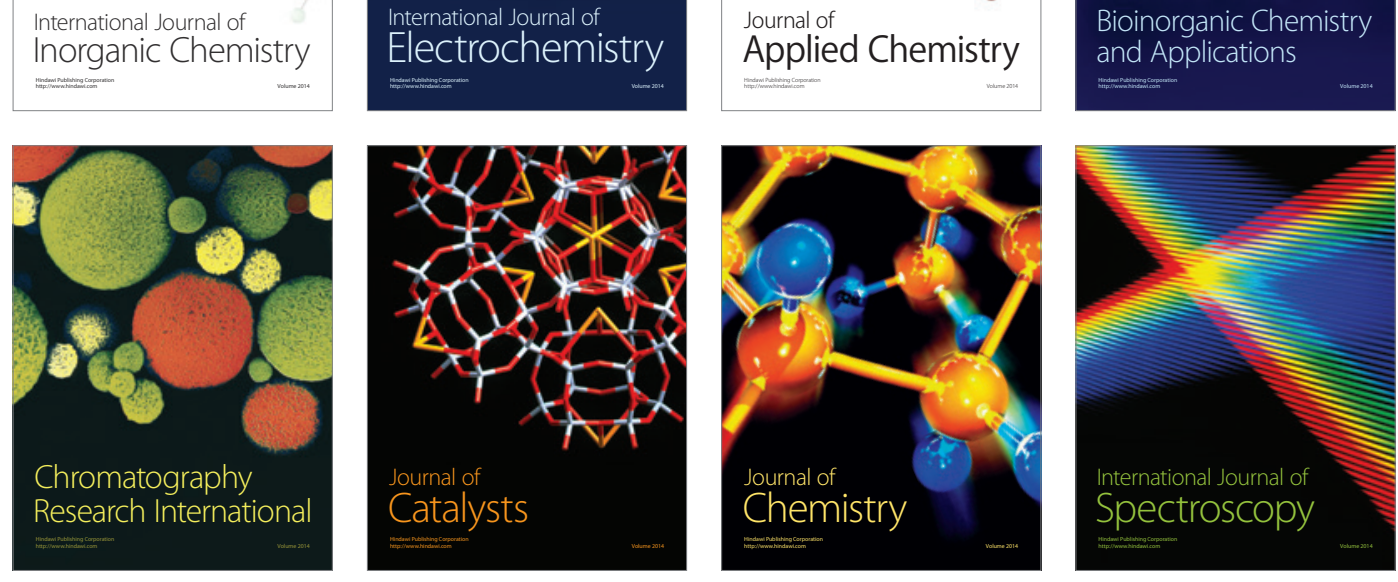